\title{
Using Unmanned Aerial Vehicles to assess the rehabilitation performance of open cut coal mines
}

\author{
Kasper Johansen a, Peter D. Erskine ${ }^{b}$, Matthew F. McCabe ${ }^{a}$
}

aWater Desalination and Reuse Center, King Abdullah University of Science and Technology, Al Jazri Building West, Thuwal, 23955-6900, Kingdom of Saudi Arabia. Emails: kasper.johansen@kaust.edu.sa; matthew.mccabe@kaust.edu.sa

${ }^{b}$ Centre for Mined Land Rehabilitation, Sustainable Minerals Institute, The University of Queensland, Brisbane, QLD 4072, Australia. Email: p.erskine@uq.edu.au

Correspondence email: kasper.johansen@kaust.edu.sa or p.erskine@uq.edu.au, phone +61-7-33464065

Word count: 8062 words (excluding Acknowledgements and References)

Word count: 9133 words (including Acknowledgements and References) 


\section{Abstract}

Mine sites are routinely required to rehabilitate their post-mining landforms with a safe, stable and sustainable land-cover. To assess these post-mining landforms, traditional on-ground field monitoring is generally undertaken. However, these labour intensive and time-consuming measurements are generally insufficient to catalogue land rehabilitation efforts across the large scales typical of mining sites ( $>100$ ha). As an alternative, information derived from Unmanned Aerial Vehicles (UAV) can be used to map rehabilitation success and provide evidence of achieving rehabilitation site requirements across a range of scales. UAV based sensors have the capacity to collect information on rehabilitation sites with extensive spatial coverage in a repeatable, flexible and cost-effective manner. Here, we present an approach to automatically map indicators of safety, stability and sustainability of rehabilitation efforts, and demonstrate this framework across three coalmine sites. Using multispectral UAV imagery together with geographic object-based image analysis, an empirical classification system is proposed to convert these indicators into a status category based on a number of criteria related to land-cover, landform, erosion, and vegetation structure. For this study, these criteria include: mapping tall trees (Eucalyptus species); vegetation extent; senescent vegetation; extent of bare ground; and steep slopes. Converting these land-cover indicators into appropriate mapping categories on a polygon basis indicated the level of rehabilitation success and how these varied across sites and age of the rehabilitation activity. This work presents a framework and workflow for undertaking a UAV based assessment of safety, stability and sustainability of mine rehabilitation and also provides a set of recommendations for future rehabilitation assessment efforts.

Keywords: open cut mine; rehabilitation; monitoring; UAV; object-based image analysis; indicators.

\section{Highlights:}

- An automatic image based processing routine was developed.

- UAV imagery was successfully used to map land-cover, landform and vegetation structure of three mine sites.

- UAV image derived information can be used to assess mine site rehabilitation status.

- A framework was designed to consistently assess the safety, stability and sustainability of mine rehabilitation. 


\section{Introduction}

In many countries, mine site rehabilitation is a mandated step that is undertaken with a goal of establishing a wide range of post-mining land uses and amenities. The redevelopment of formerly active mine sites is generally undertaken within broad goals of safety, stability, non-pollution and sustainability (here defined as the ability of a site to achieve an ecological balance to naturally maintain its landforms and vegetation cover, composition and structure) of rehabilitated landforms. Such remediation efforts are especially pertinent to open cut mining, which is a transformative process that has no obvious natural analogue, and where the local scale impacts can extend to thousands of hectares per mining operation. Significant expansion of open cut mining across the world has produced vast quantities of waste rock and spoil materials, which have been used to create new landforms (Otto, 2009). Recent estimates of rehabilitation costs (NSW Government, 2017) for recreating pre-mining landforms range from AUD\$81,000/ha for non-reactive materials up to AUD $\$ 170,000 /$ ha for more problematic materials. Creating a stable landform with an appropriate vegetation cover that is similar to, or integrated with, surrounding vegetation and then monitoring the outcomes of these efforts require an ongoing commitment by the mining company to demonstrate the evolution of these constructed landforms.

Traditional monitoring activities on mine-site rehabilitation areas are generally conducted over relatively small field plots to assess erosion, stability and ecosystem function (Erskine and Fletcher, 2013), as these metrics are routinely provided as evidence, when a mine applies for lease relinquishment. However, such field-based monitoring activities are time-consuming, cover only a small $(<0.1 \%)$ proportion of the rehabilitation site, and are often unsuited to capture the inherent spatial variability of characteristics associated with substrate, construction and rehabilitation methodology (Chen et al., 2018). To achieve rehabilitation goals, monitoring and assessment must also provide mine managers with information to allow planning and corrective management actions, while developing comprehensive data sets that demonstrate sustainability through time (Lamb et al., 2015). Therefore, alternative methods to traditional plot monitoring are required to cost-effectively inform rehabilitation efforts.

Scaling up from field-based monitoring to whole-of-mine site areas is becoming more feasible with new remote sensing technologies (Gastauer et al., 2018; McCabe et al., 2017). One such technology driving these developments has been the use of Unmanned Aerial Vehicles (UAVs) for mapping and monitoring purposes, which has advanced rapidly over the last decade (Bagheri, 2017). UAVs are generally light-weight, relatively low-cost, suitable for autonomous data collection, and highly flexible, allowing remotely sensed imagery to be collected at any time for smaller areas $\left(<1 \mathrm{~km}^{2}\right)$ under suitable weather conditions. Chen et al. (2015) highlighted the benefits of using UAV derived image data, including their high spatial resolution and ability to derive Digital Surface Models (DSM) using Structure-from-Motion for assessment of terrain, excavation stages and surface deformation of open cut mines. However, most research using UAV image data for mine sites has focussed on mapping topographic and geomorphic features (Rossi et al., 2017) rather than detailed land-cover distribution, vegetation structure and rehabilitation performance metrics.

UAV imagery has been used in many different studies for mapping vegetation and ground characteristics (Ahmed et al., 2017; Zhang and Kovacs, 2012), but only to a limited extent for mine site 
rehabilitation (Chen et al., 2015; Esposito et al., 2017). As the re-establishment of vegetation on mine sites is often one of the principal rehabilitation goals (Gastauer et al., 2018), there is potential to use existing knowledge from UAV based vegetation mapping research to support rehabilitation studies. Already, a number of research efforts have highlighted the potential of UAV based operational mapping and monitoring approaches, and identified their suitability for diverse environments, including open cut mines, and for land-cover and vegetation inventory assessments (Ahmed et al., 2017; Pajares, 2015; von Bueren et al., 2015). In related studies, Bao et al. (2014) utilized SPOT-5 satellite imagery to classify semi-arid vegetation to support mine rehabilitation and monitoring, but only managed to classify four broad land-cover classes, including tree cover, dense grassland, sparse grassland, and bare ground. However, Chen et al. (2018) emphasized the need for more detailed classes and high mapping accuracies for land-cover classification of open cut mine rehabilitation for effective monitoring. As opposed to satellite based efforts, UAV platforms allow the collection of imagery at the required spatial resolution to map detailed land-cover classes. A number of studies have argued that multi-temporal assessment of mine rehabilitation sites is needed to successfully assess its suitability for relinquishment (Fletcher and Erskine, 2013; Koch and Hobbs, 2007; Suh et al., 2017; Whiteside and Bartolo, 2016). However, in order to do this, a consistent mapping approach suited for repeated image acquisitions is paramount.

While automated image-based approaches have been investigated previously for coal mines using high-cost, high spatial resolution aerial imagery (Freeburn and Mather 2011), this study advances this objective by capturing repeat UAV imagery and developing a transferable Geographic Object-Based Image Analysis (GEOBIA) approach for rehabilitation sites. The purpose of this study was the development of novel methods for assessing the extent and progression of erosional processes and vegetation cover associated with the safety, stability and sustainability of these constructed landforms. Given this context, the research objectives include: 1) collect multi-temporal UAV imagery at several mine rehabilitation sites that cover a range of rehabilitation types, ages and land uses; 2) use these data sets to produce maps of land-cover, landform and vegetation structure to serve as metrics of rehabilitation performance; and 3) develop and apply an automatic labelling system of areas by rehabilitation status, based on the mapped land-cover, landform and vegetation structural information. The development of an automated system to detect change and condition, while providing the capacity to identify areas requiring further on-ground investigation, will be of direct benefit to other sites seeking to establish and monitor rehabilitation activities that are productive, sustainable and meet the necessary legislative requirements.

\section{Material and methods}

\subsection{Study Sites}

Rehabilitation sites, covering a range of age classes and locations, were identified across three distinct mine sites in New South Wales (Ivanhoe North) and Queensland (Meandu and Curragh), Australia (Figure 1). These mines are spread across a large geographic range and present different rehabilitation histories. The site at the highest latitude is Ivanhoe North, which lies to the west of the Blue Mountains and Sydney. The Meandu mine is located west of Brisbane, while the Curragh mine site is to the west of Rockhampton, in the Bowen Basin coalfields of central Queensland. A brief summary of the rehabilitation history for each site is detailed below. 
a
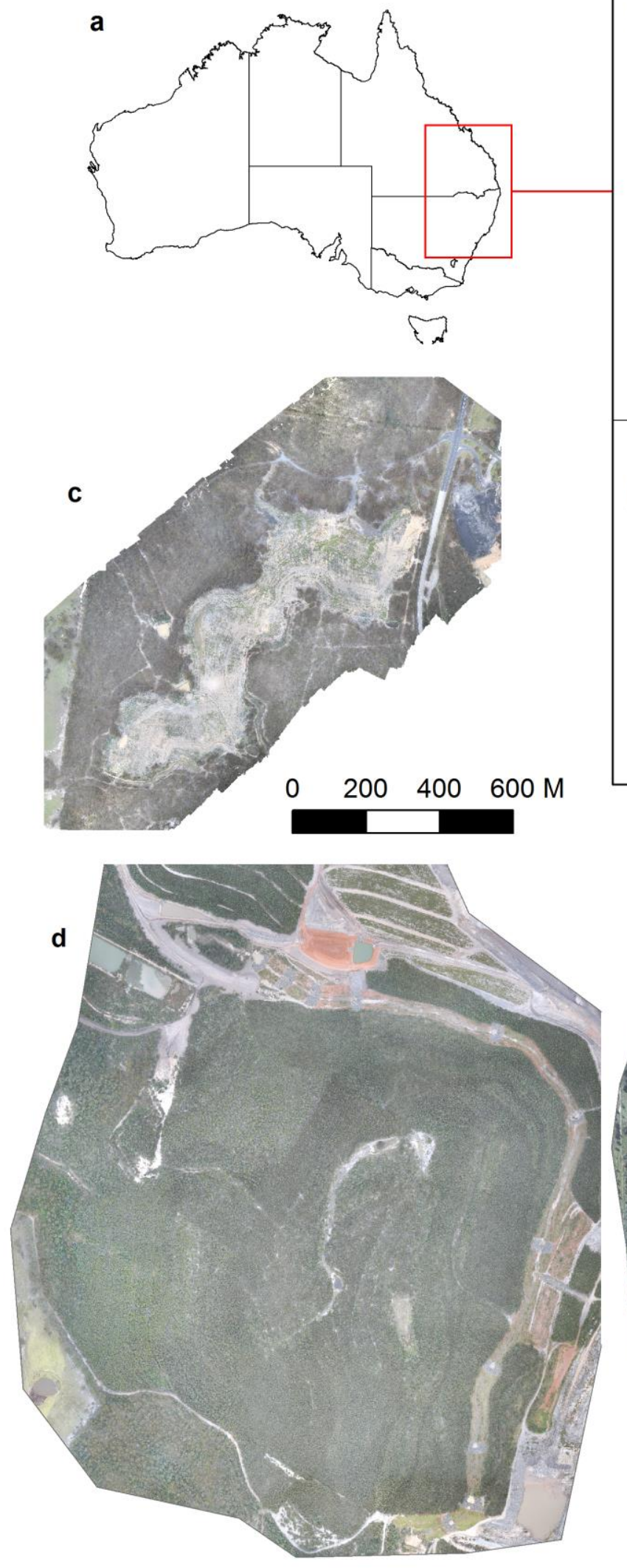
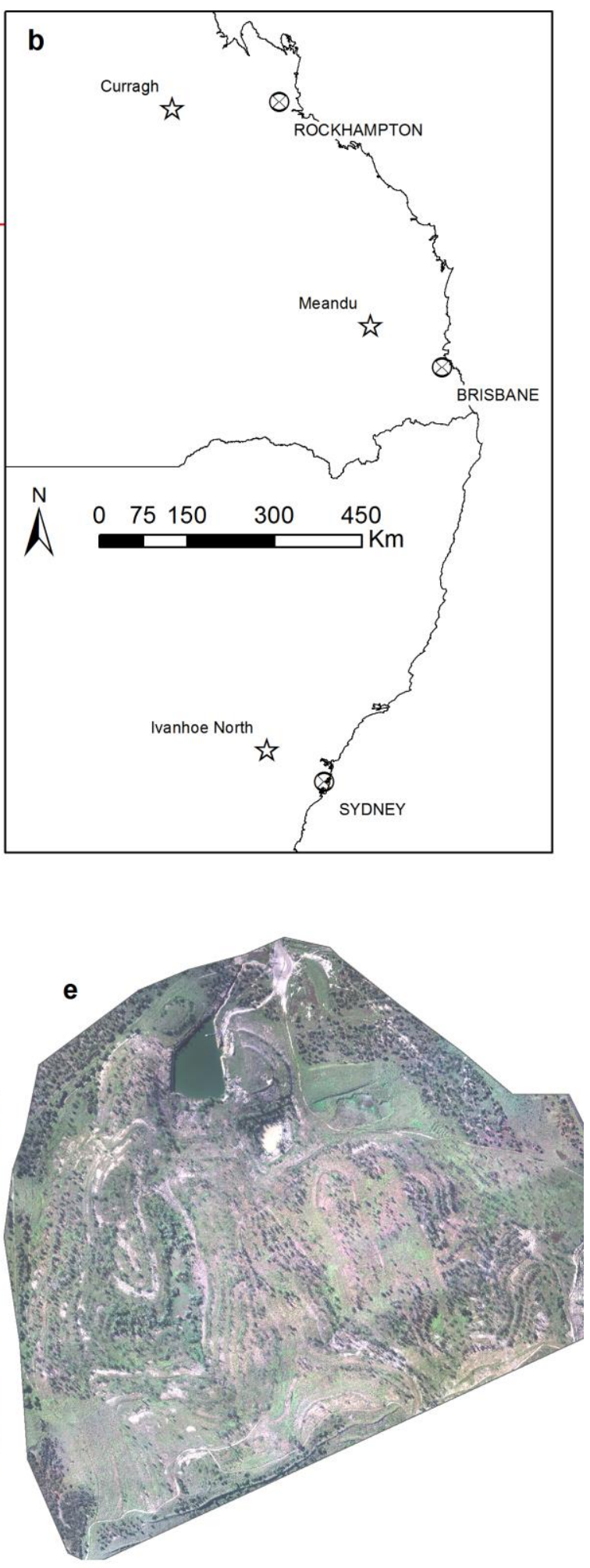

Figure 1. Locations of mines assessed in this study ( $a$ and $b$ ) and selected subsets of imagery for multitemporal assessment of (c) Ivanhoe North (d) Meandu and (e) Curragh. 


\subsubsection{Ivanhoe North}

The Ivanhoe North project was a small three-year open-cut mining operation that ceased production in March 2012. Centennial Coal, the mine operator, recovered more than 600,000 tonnes of coal over this time and progressively undertook rehabilitation activities. The main areas that required rehabilitation included the open-cut floor, the angle of repose of overburden (spoil) dumps, coarse reject dumps and abandoned high walls. This area included approximately 23 ha. Ivanhoe North's remedial works included backfilling the open cut, land contouring, soil spreading, broadcast seeding and fertilising, drainage works and the removal of buildings and pit top infrastructure. This work was completed in late 2012. The rehabilitation aims to restore the mined area to match the natural surrounding areas within the next 20 years, subject to government approval (see Figure 2a).

\subsubsection{Meandu}

Overburden has been progressively rehabilitated at the Meandu open-cut coal mine since 1985. Rehabilitation processes have included the reshaping of spoil piles to defined landform criteria and the replacement of stockpiled topsoil. Topsoil and spoil are deep ripped along the contour, sown with improved pasture and native grass, native shrubs and trees and NPK fertilizer. The seed mixes and timing of application, equipment used, stockpile age and depth of topsoil $(<400 \mathrm{~mm})$, the amount and type of fertilizer, plus the depth of ripping (300-1000 mm) have been somewhat variable over time (Gravina and Vickers 2010). For this research the southwestern areas (Figure 2b), which were rehabilitated from 1998 to 2010, were the primary areas assessed with the UAV and covered approximately 200 ha (Figure 2 b).

\subsubsection{Curragh}

The Curragh site has undergone a significant program of rehabilitation activities since the late 1980s, with more than 1100 ha rehabilitated. The main site assessed for this project was established in 1994 and is a large 180 ha landform reconstructed using the topsoil-spoil-strip method (McKenna et al. 2017a) of alternate strips (10 m wide) of bare overburden and freshly placed topsoil (to $20 \mathrm{~cm}$ depth). The block is an undulating landform. Seeding was carried out at the time of ripping and included a mix of introduced pasture grasses and legumes. On overburden strips, a range of woody Acacia and Eucalyptus tree and shrub species were sown. Over the course of this project, the landform was subjected to a controlled fire to examine the response of the rehabilitation to this type of disturbance. The progressive change of selected sites on the landform before and following the fire are illustrated in Figure 2c. 

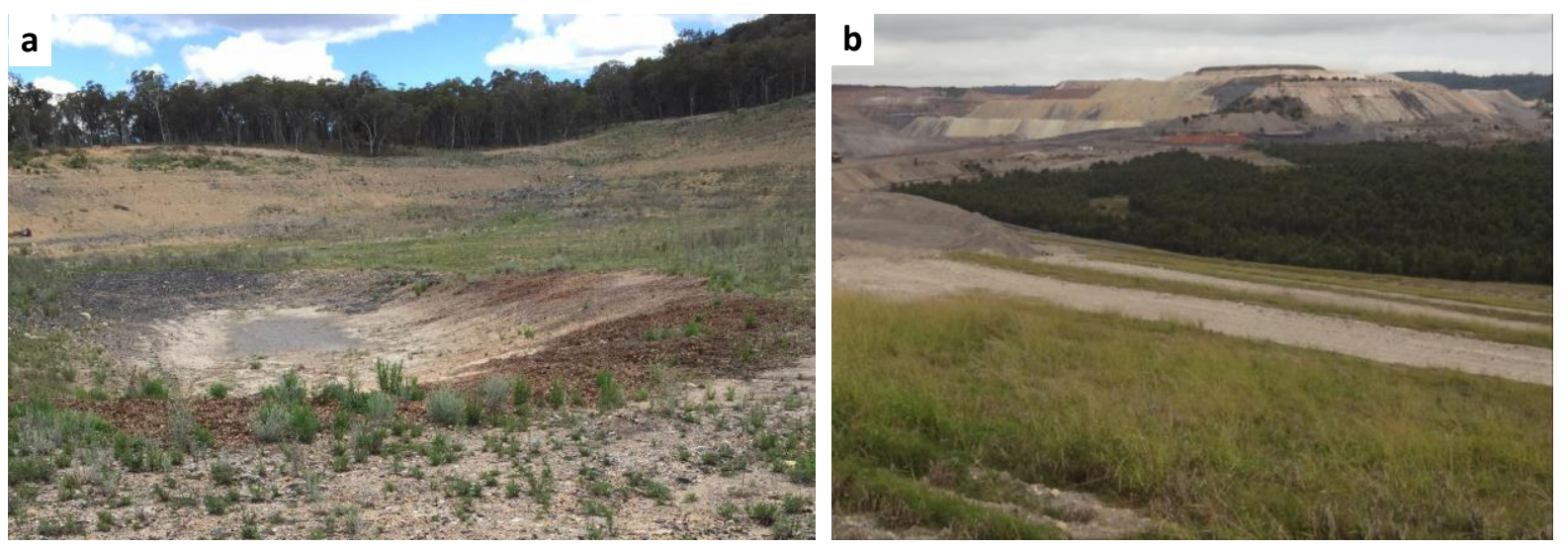

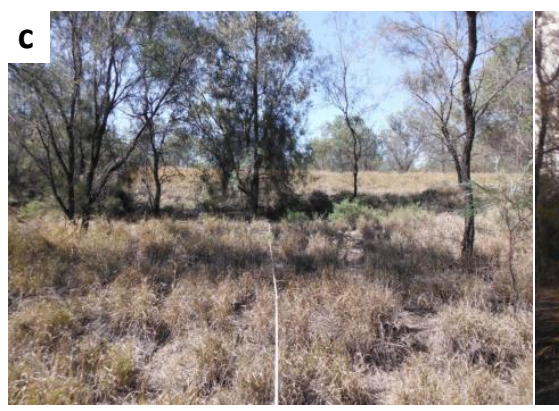

April 2015

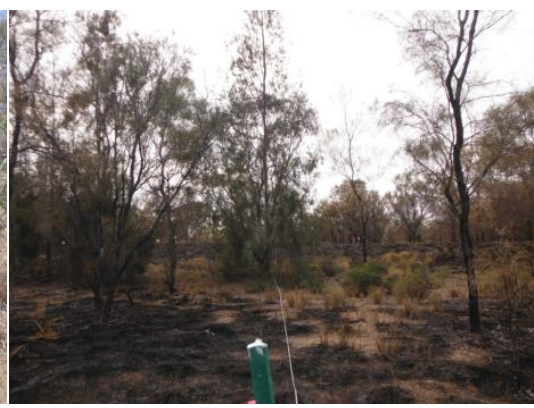

June 2015

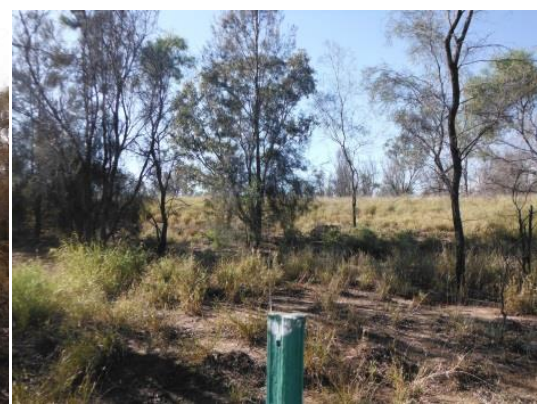

June 2016

Figure 2. (a) The eastern side of Ivanhoe North rehabilitation; (b) dense tree cover in the south-west Meandu rehabilitation area; and (c) three photos from Curragh mine, showing change in the vegetative cover of a 20 year old rehabilitation site exposed to a controlled burn on 28 May 2015, prior to the June 2015 image collection (McKenna and Glenn 2016).

\subsection{Field Data}

Rehabilitation conditions at Meandu were assessed using the BioCondition framework (Neldner and Ngugi, 2014) at sites ranging in age from 4 to 26 years. The BioCondition assessments collected multiple vegetation attributes (including basal area, stem density and cover attributes recorded for woody species) using a $200 \mathrm{~m}^{2}$ plot in August-September 2015. Curragh rehabilitation was assessed in the field within a month of each UAV image collection within $400 \mathrm{~m}^{2}$ plots (using a transect of $50 \mathrm{~m}$ ) for foliage projective cover of vegetation in three strata (canopy, understorey and ground layer) and soil surface cover along the transect (McKenna and Glenn, 2016). As the Ivanhoe North site had sparse vegetation cover (see Figure 2a), field data collection, which was carried out at the time of the UAV data collection, focused on locating woody debris and tree planting as well as the depth and width of selected gully erosion. For each UAV flight campaign, locations with senescent and photosynthetically active vegetation were field identified for these locations to serve as calibration for discriminating between these vegetation classes in the imagery.

\subsection{UAV Image Data}

Across the three mine sites, UAV imagery was collected with at least $80 \%$ forward overlap and $60 \%$ sidelap at altitudes between 100 and $120 \mathrm{~m}$ above the ground, using slightly different methods, depending upon resource availability, site access, and terrain of the covered area (Table 1). UAV operations at Ivanhoe North and the first two data collections at Curragh were consistent across the sampling periods, utilising the fixed-wing Swampfox platform with dual modified Sony A5100 sensors 
to collect red-green-blue (RGB) and near infrared (NIR) imagery. The third data collection at Curragh was undertaken using a MicaSense RedEdge multi-spectral camera. The Swampfox platform was used for the first data collection at Meandu, whilst the second collection was conducted using a fixed-wing SenseFly eBee equipped with a Parrot Sequoia multi-spectral sensor. The orthomosaics (Figure 1) and DSM generation was undertaken using the Pix4D Mapper software.

Table 1. Details of flight acquisition configurations and imagery collected by UAV platforms and sensors at the three mine rehabilitation sites.

\begin{tabular}{|c|c|c|c|c|c|}
\hline Site & $\begin{array}{l}\text { Data } \\
\text { collection } \\
\text { Time }\end{array}$ & $\begin{array}{l}\text { Flying height/ } \\
\text { Speed / Imaged } \\
\text { area / Pixel size }\end{array}$ & Platform & Sensor & Image bands ${ }^{a}$ \\
\hline Ivanhoe & Dec 2014 & $100 \mathrm{~m} / 17 \mathrm{~m} / \mathrm{s} / 2.1$ & Fixed-wing & 2 X Sony A5100 (one with & RGB, NIR \\
\hline North & Dec 2015 & $\mathrm{~km}^{2} / 0.05 \mathrm{~m}$ & Swampfox & Bayer filter removed) & \\
\hline \multirow[t]{2}{*}{ Meandu } & May 2015 & $\begin{array}{l}100 \mathrm{~m} / 17 \mathrm{~m} / \mathrm{s} / 2.9 \\
\mathrm{~km}^{2} / 0.05 \mathrm{~m}\end{array}$ & $\begin{array}{l}\text { Fixed-wing } \\
\text { Swampfox }\end{array}$ & $2 \times$ Sony A5100 & RGB, NIR \\
\hline & May 2016 & $\begin{array}{l}120 \mathrm{~m} / 14 \mathrm{~m} / \mathrm{s} / 2.9 \\
\mathrm{~km}^{2} / 0.18 \mathrm{~m}\end{array}$ & $\begin{array}{l}\text { Fixed-wing } \\
\text { SenseFly eBee }\end{array}$ & Parrot Sequoia & $R, G, R E, N I R$ \\
\hline \multirow[t]{2}{*}{ Curragh } & $\begin{array}{l}\text { Apr } 2015 \\
\text { Jun } 2015\end{array}$ & $\begin{array}{l}120 \mathrm{~m} / 17 \mathrm{~m} / \mathrm{s} / 2.1 \\
\mathrm{~km}^{2} / 0.06 \mathrm{~m} \mathrm{(2014}\end{array}$ & $\begin{array}{l}\text { Fixed-wing } \\
\text { Swampfox }\end{array}$ & $\begin{array}{l}2 \times \text { Sony } A 5100 \text { (one with } \\
\text { Bayer filter removed) }\end{array}$ & RGB, NIR \\
\hline & Jun 2016 & $\begin{array}{l}\text { and 2015) and } 0.10 \\
m(2016)\end{array}$ & & MicaSense RedEdge & RGB, RE, NIR \\
\hline
\end{tabular}

a $R=$ Red, $G=$ Green, $B=B l u e, R E=$ red edge, $N I R=$ near infrared

\subsection{Mapped Parameters}

Open cut mine and rehabilitation sites are highly heterogeneous spectrally, which often prevents successful image based land-cover classification using conventional approaches (Cheng et al., 2018). However, GEOBIA is ideally suited for high spatial resolution image data such as UAV imagery, and can integrate additional information such as shape, size, context and multi-scale characteristics (Bao et al., 2014; Blaschke, 2010; Johansen et al., 2010). A number of land-cover classes were identified as being directly related to the assessment of safety, stability and sustainability of mine sites undergoing rehabilitation (Esposito et al., 2017; Cheng et al., 2018; Whiteside et al., 2014). These land-cover classes were selected because: 1 ) they are directly related to safety, stability and sustainability of mine sites undergoing rehabilitation; and 2) they have potential to be classified using not just spectral information, but also height information derived from Structure-from-Motion, e.g. trees, and shape and size characteristics, e.g. roads are elongated areas with consistent width. Specific land-cover classes derived from the UAV imagery included:

- Bare ground: areas of sand, gravel, or rock.

- Gully: incision in the landscape caused by concentrated flows.

- Road: elongated areas of bare ground with little variation in width.

- Senescent vegetation: non-photosynthetically active (based on field observations) vegetation.

- Shadows: areas affected by landscape features above ground level casting shade.

- Steep slopes in areas with bare ground: slope $>10^{\circ}$ in areas mapped as bare ground. 
- Grass or low shrub: photosynthetically active (based on field observations) and $<0.5 \mathrm{~m}$ in height.

- Shrub and other vegetation < $2 \mathrm{~m}$ : photosynthetically active and between 0.5-2 $\mathrm{m}$ in height.

- Trees 2-4 $\mathrm{m}$ in height: based on a height from ground level to the apex between 2-4 m.

- Trees $>4 \mathrm{~m}$ in height: based on a height from ground level to the apex of the crown $>4 \mathrm{~m}$.

- Water bodies: any area with open water, e.g. a dam.

The land-cover maps produced from the UAV imagery were validated against field data and points visually identified on the original UAV imagery. In the field and visual assessment used for validation, an area with dead trees or trees with no foliage were assigned as the dominant land-cover type from an aerial view instead, i.e. often shrub, grass or senescent vegetation, to correspond to the mapping scale of the GEOBIA. An error matrix was produced for each land-cover map. The overall, user, and producer accuracies were employed to assess the accuracy of the land-cover maps, with overall accuracy, representing the proportion of all reference sites that are correctly mapped, user accuracy being $100 \%$ minus commission error (i.e. false positives), and producer accuracy being $100 \%$ minus omission error (i.e. false negatives) (Congalton and Green, 1999).

\subsection{Geographic Object-Based Image Analysis}

For UAV imagery with small pixel sizes (in this case, 0.05-0.20 m), the pixels will in most cases be smaller than the features being mapped. Hence, each feature, such as a tree crown or patch of bare ground, will consist of multiple pixels. Variations in reflectance characteristics within a single feature e.g. because of leaf clumping, canopy gaps, sunlit side of tree crown versus shaded side, often make it challenging to use pixel-based approaches for land-cover mapping, as pixels belonging to an individual feature appear spectrally different (Blaschke, 2010). Hence, GEOBIA is well suited for UAV image data sets collected at high spatial resolution.

The site specific image data sets had varying pixel sizes due to the camera types used and differences in flying heights and terrain (see Table 1). To standardise the image processing to a uniform scale, a pixel size of $0.20 \mathrm{~m}$ was selected, as this represented the largest pixel size of the collected data sets, while still meeting the high-resolution requirements for mapping all of the required land-cover classes. As the data sets were still computationally intensive to process at this pixel size, the workflow was based on a batch-processing approach of individual image polygons. These polygons represented an outline of different rehabilitation sites based on their age and characteristics and were provided by the mining companies as shapefiles. These included 2,10 and 17 delineated polygons for the mapped areas of Ivanhoe North, Curragh and Meandu, respectively. Each of the polygons were segmented into fine scale objects for land-cover classification using an automated mapping approach.

The automated mapping approach was designed as a rule set in the eCognition Developer 9.2 software. The overall workflow of this process is presented in Figure 3. As none of the UAV image data sets were radiometrically, vignette or BRDF corrected to at-surface reflectance (to reflect an "applications" based usage of UAVs, as opposed to research purposes), consistency in spectral reflectance of the same features could not be expected. Hence, some threshold values used several times in the rule set were specified as a "variable", representing a set value specified only once in the rule set, rather than each time this threshold was used within the rule set. Hence, a change in threshold values would only require the updating of the variable in one location of the rule set to 
ensure its suitability to each image data set. Those thresholds that were deemed to be different in different image data sets, because of the omission of the radiometric, vignette and BRDF corrections, were set, using a variable, so that these thresholds could be easily edited within the rule set to account for the omission of image data corrections.

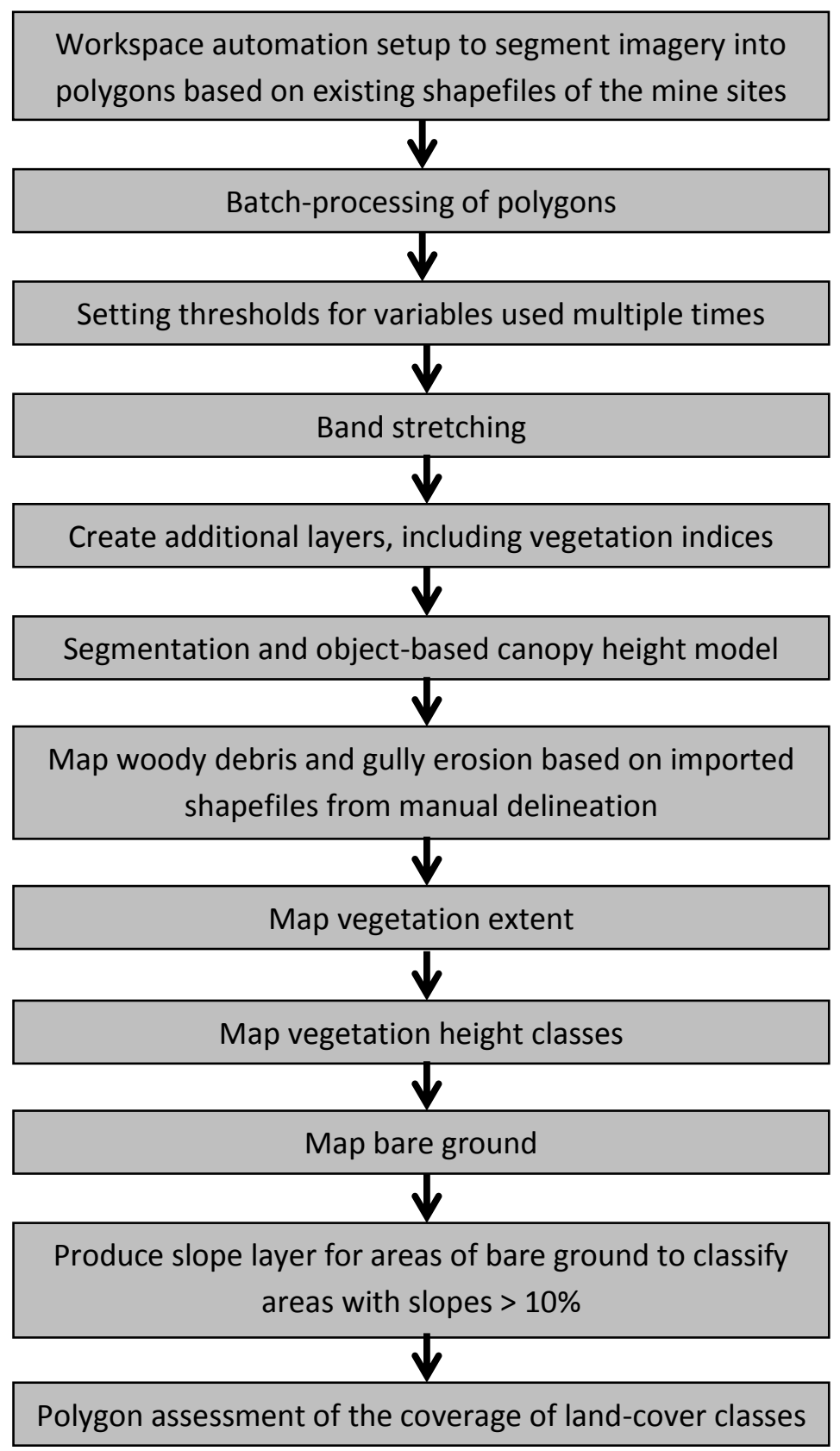

Figure 3. Flowchart of the image processing approach used to convert the UAV imagery into a landcover map.

As the spectral bands of the UAV imagery did not cover the full range of the digital number range, each spectral band was stretched to cover the full range. These stretched bands were subsequently used in the remainder of the rule set. The next step produced various vegetation indices, such as the Normalised Vegetation Difference Vegetation index and the Green Ratio index (Pickup et al., 1993; 
Kerr and Ostrovsky, 2003). An object-based canopy height model was also developed, based on the DSM and the assumption that the lowest location within a tree's or shrub's neighbouring area would represent the elevation of the ground (Jimenez-Brenes et al., 2017; Torres-Sanchez et al., 2015). A fine scale segmentation (multiresolution segmentation algorithm, scale factor $=5$, shape $=0.1$, compactness $=0.5$ ) based only on the DSM layer was first performed to cluster pixels together with similar elevation. The difference in elevation between the lowest location (the fine scale object with the lowest DSM value) and all other nearby objects was then used to estimate the height of features above ground level. This required the search area of the lowest elevation to be large enough to include gaps in the canopy or areas of bare ground, but small enough to avoid variation in ground elevation. A search window of $50 \mathrm{~m} \times 50 \mathrm{~m}$ was found feasible in areas with trees. This search window was further reduced to $20 \mathrm{~m} \times 20 \mathrm{~m}$ for areas with sparse tree coverage, as this made it easier to identify areas with bare ground.

Areas with ground and canopy vegetation were mapped using vegetation indices and thresholds of these. Thresholds of vegetation indices were set according to coincident field based observations to discriminate photosynthetically active and senescent vegetation. If areas smaller than 6 pixels were not classified as vegetation but were completely surrounded by vegetation, these were also classified as vegetation. If areas smaller than 4 pixels were classified as vegetation but were surrounded by pixels yet to be classified, these small vegetation patches were unclassified to avoid excessive details.

The mapped vegetation and the object-based canopy height information were used to map trees $>4$ $\mathrm{m}$, trees between 2-4 m, shrub and other vegetation between 0.50-2 m, as well as grass and low shrub of $<0.50 \mathrm{~m}$ in height. To avoid a tree being mapped with multiple height classes, because parts of the crown may occur at various height intervals, trees with a classified maximum height were grown outwards using a region-growing algorithm, so that the entire tree crown area appeared with the same height class as the tree apex.

Bare ground was mapped using brightness for all four spectral bands and vegetation indices. Once mapped, the slope of these areas was calculated and bare ground areas with a slope $>10 \%$ were classified as steep slopes. If the edges of tree crowns were not accurately mapped, this caused the DSM to show an abrupt change in elevation because of the height differences between the tree edge and the ground over a short horizontal distance. To avoid this issue, a buffer of $2 \mathrm{~m}$ was created surrounding tree crown edges to exclude these areas in the calculation of slope.

The derived land-cover information was used to assess the safety, stability and sustainability within each polygon of the rehabilitation sites. A polygon assessment was following the rule-based framework explained in Table 2 below. Pixels with > 10\% slope were merged, and the object length of these was calculated. All objects classified as bare ground were merged and if their area covered $>1000 \mathrm{~m}^{2}$ then these were reclassified as "bare ground $>1000 \mathrm{~m}^{2 \prime}$. The percentage coverage within a polygon of photosynthetically active ground and canopy cover was assessed by calculating the total area of grass, shrub and trees in relation to the total polygon area. Canopy cover within a polygon was assessed by calculating the total area of trees $>2 \mathrm{~m}$ in height in relation to the total polygon area. As a surrogate for species, height classes (i.e. 2-4 $\mathrm{m}$ and $>4 \mathrm{~m}$ tree heights) were used. This is based on the assumption that different tree species in coal mine rehabilitation often appear with different heights, e.g. Acacia and Eucalyptus trees will often occupy different height intervals (Erskine and 
Fletcher 2013). Woody debris was only present at the Ivanhoe North site, but in most cases the trunks had similar brightness to bare ground. Hence, these could not be reliably mapped unless manual delineation was undertaken. Given this, it is recommended to manually delineate the woody debris prior to the eCognition processing and include these delineated areas as a shapefile. The rule set was designed to look for this shapefile to ensure the whole process for the larger area mapping could be undertaken automatically. Roads were mapped based on their elongated shape and narrow width of bare ground.

\subsection{Development of Framework and a Decision Based Approach}

Considering the mapped classes outlined above, a number of conditions were incorporated into the rule set to automatically label each polygon to one of five status categories. At the end of the rule set, the polygon status map and the land-cover and vegetation structure maps, including information on the indicators outlined in Table 2, were exported for visualisation and further GIS analysis. Based on the mapped land-cover types and indicators, Table 2 was used to categorise each polygon within the mapped areas into five status levels, based on safety, stability and sustainability:

- Category 1: If either A or B or both A and B were not fulfilled, this would require site rework as the site was deemed unstable and unsafe.

- Category 2: If A and B, but not C, were fulfilled, this means the site was safe but not stable and sustainable.

- Category 3: If A, B and C were all fulfilled and none of the other indicators were achieved, this would mean that the site was safe and stable, but that it had not achieved a level of sustainability.

- Category 4: If A, B and C were all fulfilled and some, but not all, of the other indicators (D-H) were achieved, this would mean that the site was safe and stable, but that it had only achieved some level of sustainability.

- Category 5: If all indicators (A-H) were achieved, this would mean that the site was safe, stable and sustainable.

Table 2. Specific thresholds to be achieved for each indicator to accomplish a high status of safety, stability and sustainability (at the polygon level) for each of the three mine sites. Some of the mine sites had different thresholds. These thresholds were set based on input from the mining companies in relation to each rehabilitation polygon's age, environment, landscape and vegetation surrounding the mine site, and rehabilitation efforts and expectations.

\begin{tabular}{|lllll|}
\hline \multicolumn{1}{c}{$\begin{array}{c}\text { Indicators in } \\
\text { rehabilitation polygons }\end{array}$} & \multicolumn{1}{c|}{ Curragh } & Ivanhoe North & \multicolumn{1}{c|}{ Meandu } \\
\hline A & $\begin{array}{l}\text { Slope in areas with bare } \\
\text { ground (slope towards a } \\
\text { waterway is worse than } \\
\text { towards pit) }\end{array}$ & $\begin{array}{l}<10 \% \text { slope }<100 \\
\mathrm{~m} \text { long or }<10-20 \% \\
\text { slope }<30 \mathrm{~m} \text { long }\end{array}$ & $\begin{array}{l}<10 \% \text { slope }<100 \\
\mathrm{~m} \text { long or }<10-20 \% \\
\text { slope }<30 \mathrm{~m} \text { long }\end{array}$ & $\begin{array}{l}<10 \% \text { slope }<100 \mathrm{~m} \\
\text { long or }<10-20 \% \\
\text { slope }<30 \mathrm{~m} \text { long }\end{array}$ \\
\hline B & Erosion (gullies/rills) & $\begin{array}{l}<50 \mathrm{~cm} \text { rills (after } \\
5 \text { years), }<1 \mathrm{~m} \text { in } \\
\text { rock drains }\end{array}$ & $\begin{array}{l}<50 \mathrm{~cm} \text { rills (after } \\
5 \text { years), }<1 \mathrm{~m} \text { in } \\
\text { rock drains }\end{array}$ & $\begin{array}{l}<50 \mathrm{~cm} \text { rills (after } 5 \\
\text { years), }<1 \text { m in rock } \\
\text { drains }\end{array}$ \\
\hline C & Contiguous bare ground & $\begin{array}{l}<1000 \mathrm{~m}^{2},<50 \% \text { of } \\
\text { polygon }\end{array}$ & $\begin{array}{l}<500 \mathrm{~m}^{2},<50 \% \text { of } \\
\text { polygon }\end{array}$ & $\begin{array}{l}<500 \mathrm{~m}^{2},<50 \% \text { of } \\
\text { polygon }\end{array}$ \\
\hline
\end{tabular}




\begin{tabular}{|c|c|c|c|c|}
\hline D & $\begin{array}{l}\text { Photosynthetically } \\
\text { active ground and } \\
\text { canopy cover }\end{array}$ & $>50 \%$ & $>50 \%$ & $>50 \%$ \\
\hline $\mathbf{E}$ & $\begin{array}{l}\text { Canopy cover ( } 2 \mathrm{~m} \\
\text { height) }\end{array}$ & $>5 \%$ (after 5 years) & $\begin{array}{l}>30 \% \text { (after } 5 \\
\text { years) }\end{array}$ & $\begin{array}{l}50-70 \% \text { (after } 5 \\
\text { years) }\end{array}$ \\
\hline $\mathbf{F}$ & $\begin{array}{l}\text { Canopy or framework } \\
\text { species indicator (trees } \\
\text { within both the } 2-4 \mathrm{~m} \\
\text { and }>4 \mathrm{~m} \text { threshold) }\end{array}$ & $\geq 2$ & $\geq 2$ & $\geq 2$ \\
\hline G & Woody debris & Not a concern & $>5 \%$ cover & Present \\
\hline $\mathbf{H}$ & $\begin{array}{l}\text { Roads (contributor to } \\
\text { erosion due to runoff) }\end{array}$ & Absent & Absent & Absent \\
\hline
\end{tabular}

\section{Results and Discussion}

\subsection{Land-Cover Mapping}

Accurate mapping of land-cover classes is a key requirement, as these form the input data for the generation of the rehabilitation status maps. The developed GEOBIA mapping routine was found to be transferable between all image data sets (with the exception of adjusting three vegetation index thresholds and those presented in Table 2), i.e. the same rule set could be used for processing all the image data sets to produce the land-cover maps. As can be seen from Figure 4, the maps produced for the two images of Ivanhoe North were similar, with the main differences being an increase in grass and low shrub and a reduction of bare ground, occurring in the 12 months between the images. As the same platform, camera and flight acquisition configurations were used for the two data collections at Ivanhoe North, variations in the DSM were attributed to changes in vegetation structure and greenness in response to rainfall and rehabilitation efforts. Overall, the DSM's produced realistic height differences between ground and elevated features such as shrubs and trees when using the object-based canopy height model approach in the rule set. The rule set used for the Ivanhoe North imagery generated overall mapping accuracies of $85 \%$ and $87 \%$ for images 1 and 2 , respectively (see Appendix 1: Tables A1 and A2). 

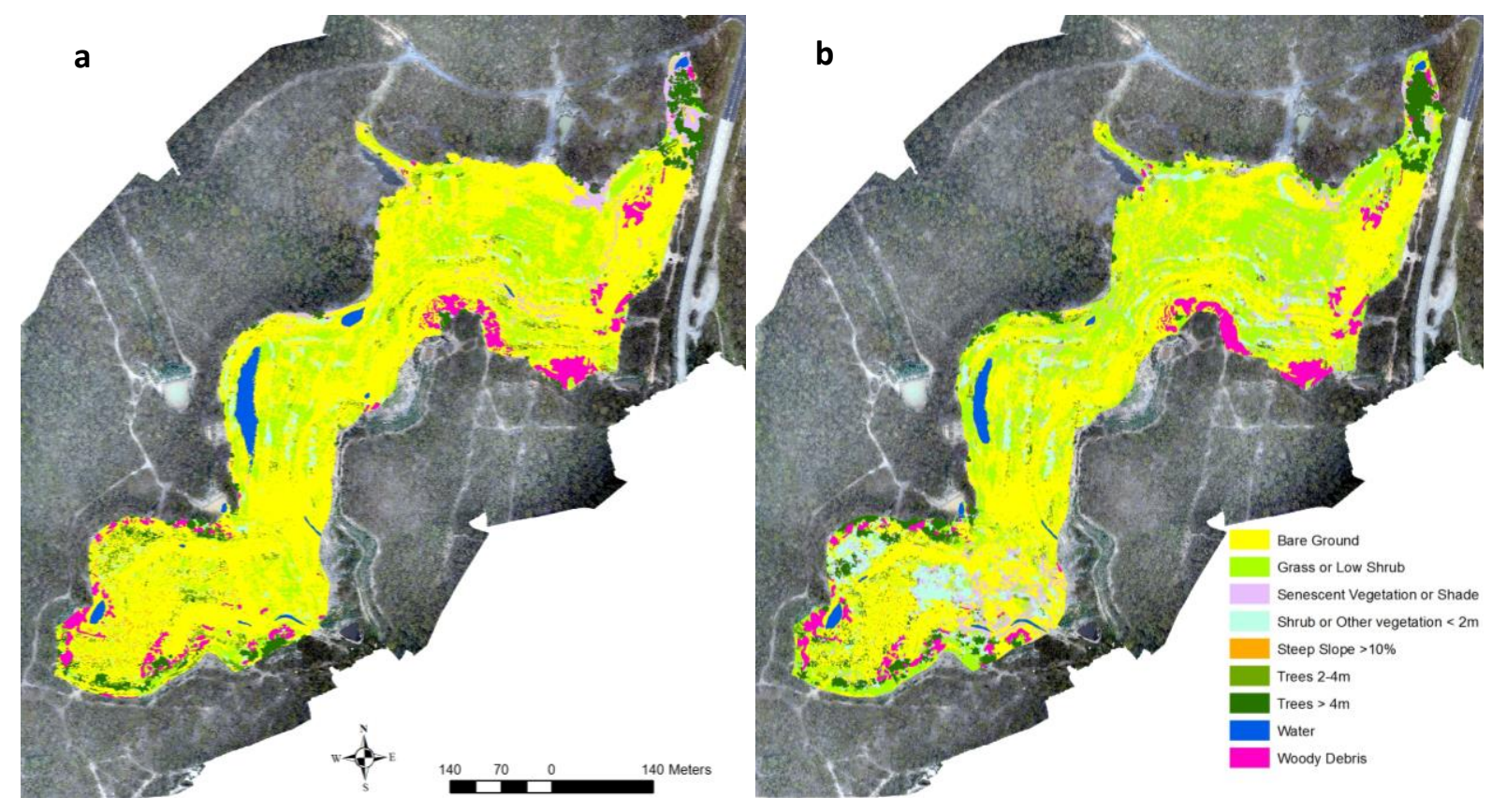

Figure 4. Land-cover maps of the Ivanhoe North site based on UAV images 1 (a) and 2 (b) collected in December 2014 and December 2015, respectively.

Based on the classifications of the two images of Ivanhoe North, image 2 had more vegetative groundcover but less water. The DSM differences between the images resulted in a larger area being classified as shrub in image 2, possibly because of influences from both rehabilitation efforts and rainfall prior to the image data collections. This contributed to a larger area of bare ground being mapped in image 1 compared to image 2 (Table 3).

Table 3. Spatial coverage and percentage distribution of land-cover classes for Ivanhoe North images 1 and 2.

\begin{tabular}{lcc}
\hline Land-Cover Type & Image 1 Coverage $\left(\mathbf{m}^{2}\right)$ & Image 2 Coverage $\left(\mathbf{m}^{\mathbf{2}}\right)$ \\
\hline Bare Ground & $148,744(64.1 \%)$ & $107,528(46.3 \%)$ \\
Grass or Low Shrub & $34,786(15.0 \%)$ & $60,397(26.0 \%)$ \\
Senescent Vegetation or Shade & $7,740(3.3 \%)$ & $15,459(6.7 \%)$ \\
Shrub $<$ 2 m in height & $8,651(3.7 \%)$ & $18,265(7.9 \%)$ \\
Steep slope on bare ground & $1,208(0.5 \%)$ & $225(0.1 \%)$ \\
Trees $>4$ m & $8,828(3.8 \%)$ & $11,247(4.8 \%)$ \\
Trees 2-4 m & $6,979(3.0 \%)$ & $5,933(2.6 \%)$ \\
Water & $4,617(2.0 \%)$ & $3,050(1.3 \%)$ \\
Woody Debris & $10,446(4.5 \%)$ & $9,895(4.3 \%)$ \\
\hline
\end{tabular}

The land-cover maps produced for the Curragh site showed similar trends in land-cover distribution (Figure 5). The classification of trees $>2 \mathrm{~m}$ revealed high user and producer accuracies for the second and third images $(>88 \%)$. Some misclassification occurred between shrub and grass. This was attributed to several locations with both grasses and shrub having heights close to the $0.50 \mathrm{~m}$ threshold used to discriminate these two land-cover classes. Image 1 presented high levels of errors of commission (false positives, i.e. overestimation) and omission (false negatives, i.e. underestimation), with only $20 \%$ of the trees mapped correctly and $50 \%$ of mapped trees belonging 
to other land-cover classes (Appendix 1, Tables A3-A5). The main reason for this was the poor quality of the point cloud generation and derived DSM, which prevented several trees from being automatically mapped. Several tree crowns with very sparse canopy cover in image 1 , had no canopy cover in image 2 after the fire (and were hence correctly characterized as the dominant land-cover class, e.g. grass or shrub, instead) and increased green canopy cover in image 3 after post-fire regrowth. Sparse vegetation and crown cover are likely to cause a less dense point cloud with fewer matching points between overlapping photos. This may cause the DSM to be less accurate, as the highest recorded points of trees and shrub within the point cloud, which the DSM generation is based upon, may not represent their apex. Hence, the DSM produced for image 1 caused discrepancies in the differentiation between trees $>2 \mathrm{~m}$ and shrubs $<2 \mathrm{~m}$, grass, and senescent vegetation. To avoid these issues in the future, increasing the overlap between flight lines and flying lower and slower may improve the quality of the generated point cloud and DSM (Pix4D, 2018). However, flying lower and slower will compromise the size of the area that can be covered within one flight, with the overall data collection process taking longer. This will also increase the likelihood of introducing cloud shadows and differing illumination characteristics into the imagery because of the movement of the sun throughout the flight operation (Johansen et al., 2018; McKenna et al., 2017b). It may also prevent required flights from being undertaken around solar noon and hence will increase shadows from trees and other features above ground level, which may require shadows to be masked to improve mapping accuracies (McKenna et al., 2017b).
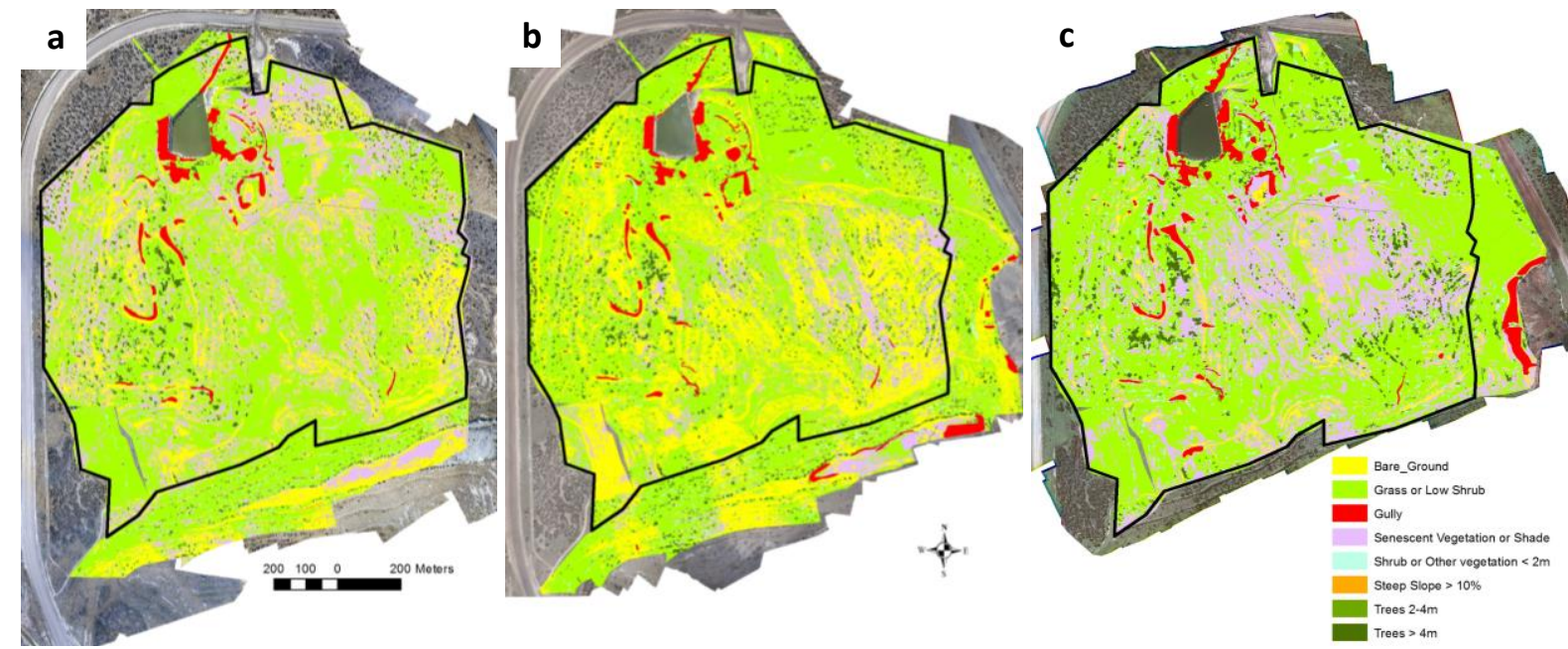

Figure 5. Land-cover maps of the Curragh site based on UAV images 1 (a), 2 (b) and 3 (c) collected in April 2015, June 2015 and June 2016, respectively. The polygon outline indicates the common focus area within which land-cover changes were quantified.

The proportions of bare ground, senescent vegetation and grass cover varied between the three images of Curragh (Table 4), due primarily to the effects of the controlled fire disturbance, which occurred on 28 May 2015. However, the producer accuracy of mapped shrub was generally low $(<39 \%)$, as several sites with shrub were incorrectly classified due to tall grass and similar multispectral characteristics between shrub and grass in some places with sparse cover. Grass cover was misclassified as senescent vegetation in some cases in images 1 (15 out of 38) and 2 (22 out of 54), which was often caused by variations in background soil type and colour. Despite of this, a distinct increase in mapped bare ground in image 2, mainly at the expense of a reduction in senescent 
vegetation, was attributed to the controlled fire prior to the data collection of image 2 . An increase in gully erosion, and grass, shrub and tree cover could also be observed over time.

Table 4. Spatial coverage and percentage distribution of land-cover classes for the Curragh site for images 1, 2 and 3 . As the total area covered differed between the images, only land-covers, occurring within the common focus area outlined in Figure 5, are included.

\begin{tabular}{lccc}
\hline Land-Cover Type & $\begin{array}{c}\text { Image } \mathbf{1} \text { Coverage } \\
\left(\mathbf{~}^{\mathbf{2}}\right)\end{array}$ & $\begin{array}{c}\text { Image 2 Coverage } \\
\left(\mathbf{m}^{\mathbf{2}}\right)\end{array}$ & $\begin{array}{c}\text { Image 3 Coverage } \\
\left(\mathbf{m}^{\mathbf{2}}\right)\end{array}$ \\
\hline Bare Ground & $231,969(16.4 \%)$ & $458,653(32.5 \%)$ & $54,112(3.8 \%)$ \\
Grass or Low Shrub & $703,814(49.9 \%)$ & $682,679(48.4 \%)$ & $775,539(54.9 \%)$ \\
Gully & $30,834(2.2 \%)$ & $31,156(2.2 \%)$ & $40,884(2.9 \%)$ \\
Senescent Vegetation or Shade & $362,156(25.7 \%)$ & $153,159(10.8 \%)$ & $396,155(28.1 \%)$ \\
Shrub < 2 m in height & $30,366(2.2 \%)$ & $27,568(2.0 \%)$ & $64,826(4.6 \%)$ \\
Steep slope on bare ground & $44(0.003 \%)$ & $40(0.003 \%)$ & $138(0.01 \%)$ \\
Trees > 4 m & $28,681(2.0 \%)$ & $39,263(2.8 \%)$ & $35,493(2.5 \%)$ \\
Trees 2-4 m & $23,905(1.7 \%)$ & $19,251(1.4 \%)$ & $44,622(3.2 \%)$ \\
\hline
\end{tabular}

At the Meandu site, vegetation (including trees, shrub and grass) was accurately mapped in both images. However, some misclassification occurred within the individual vegetation classes. Trees and shrub were underestimated in image 2, i.e. only $60.6 \%$ and $33.3 \%$ of field-identified trees and shrub were correctly mapped. The main cause of these mapping errors was the poor quality of the produced DSM for image 2, omitting many trees and shrub in the point cloud and subsequent DSM, causing overestimation of grass cover (commission error $=49 \%$ ) (Appendix 1, Tables A6 and A7). These effects are visible in Figure 6 and Table 5. It is important to note that image 2 was collected using a different sensor (Parrot Sequoia), producing a lower spatial resolution ( $0.18 \mathrm{~m}$ pixels compared to $0.05 \mathrm{~m}$ pixels) than that of image 1 (collected with a Sony A5100). As a result, the inability of this sensor to identify features elevated above ground level caused the errors of omission for mapped trees and shrub, while overestimating grass cover. This effect has been identified recently in other studies, where increasing flying heights of $30 \mathrm{~m}, 50 \mathrm{~m}$ and $70 \mathrm{~m}$ gradually degraded the quality of the produced DSM and the ability to accurately estimate the height of trees above ground level (Johansen et al., 2018). 

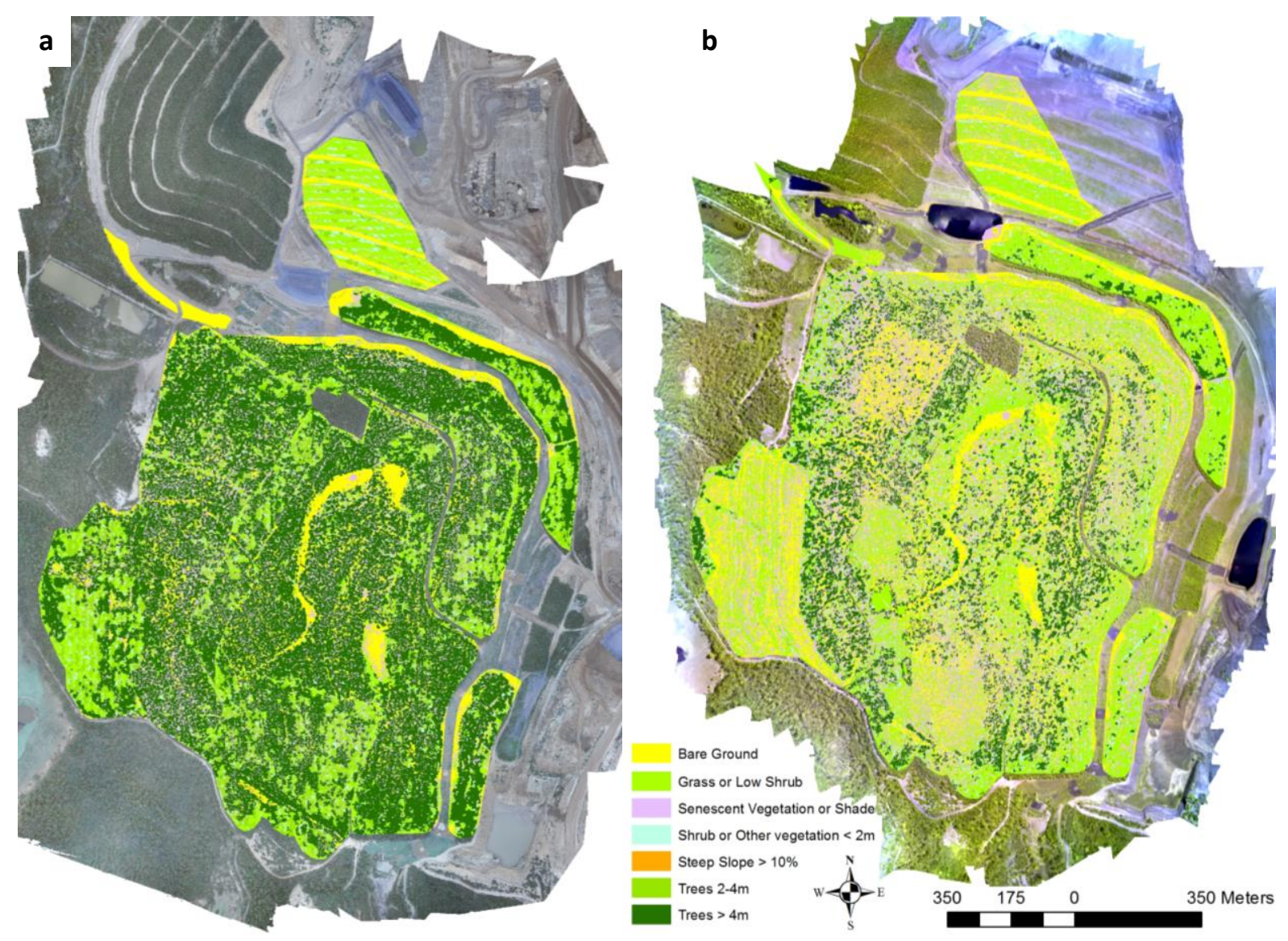

Figure 6. Land-cover maps of the Meandu site based for UAV images 1 (a) and 2 (b).

Table 5. Spatial coverage and percentage distribution of land-cover classes for the Meandu site for images 1 and 2.

\begin{tabular}{lcc}
\hline Land-Cover Type & Image 1 Coverage $\left(\mathbf{m}^{2}\right)$ & Image 2 Coverage $\left(\mathbf{m}^{2}\right)$ \\
\hline Bare Ground & $136,226(8.5 \%)$ & $342,078(21.2 \%)$ \\
Grass or Low Shrub & $185,351(11.5 \%)$ & $452,665(28.1 \%)$ \\
Senescent Vegetation or Shade & $219,152(13.6 \%)$ & $419,965(26.1 \%)$ \\
Shrub < 2 m in height & $78,063(4.8 \%)$ & $95,939(6.0 \%)$ \\
Steep slope on bare ground & $1,133(0.1 \%)$ & $279(0.02 \%)$ \\
Trees > 4 m & $839,128(52.1 \%)$ & $228,665(14.2 \%)$ \\
Trees 2-4 m & $150,972(9.4 \%)$ & $70,408(4.4 \%)$ \\
\hline
\end{tabular}

\subsection{Mapping Rehabilitation Status}

To enable an automated approach for labelling the mine site polygons into categories of status (Table 2), the steps outlined in Figure 7 were implemented as part of the rule set in the eCognition software. The approach developed for categorising the mine site polygons into five different safety, stability and sustainability levels was based on the land-cover classification results. As it is not always possible to achieve high land-cover mapping accuracies for mine sites (Bao et al., 2014; Cheng et al., 2018), the developed approach did not rely as heavily on accurate classification. This was achieved, as the framework for polygon assessment (Figure 7) was developed using features and thresholds (e.g. > 500 $\mathrm{m}^{2}$ bare ground, canopy cover $>0 \%$, road cover $=0$, etc.) that would not have significant effects on the categorisation of the polygons, if land-cover mapping inaccuracies were present. However, 
polygons with land-cover percentages close to the set framework thresholds may be more vulnerable to mapping inaccuracies (Johansen et al., 2007). As such, it is important to ensure that the UAV imagery collected is suitable for producing high quality DSMs, as the higher the mapping accuracies are, the more reliable the framework results become. The inclusion of at least one near infrared band is also preferred in order to apply the framework to accurately map vegetation characteristics and discriminate senescent vegetation and photosynthetically active vegetation. 
Calculate the percentage coverage of the following land-cover classes within each polygon:

- Gullies;

- Bare ground objects $>500 / 1000 \mathrm{~m}^{2}$;

- Trees 2-4 m;

- Trees $>4 \mathrm{~m}$;

- Combined photosynthetically active ground and canopy cover (trees, shrub and grass) ;

- Trees 2-4 m and Trees $>4 \mathrm{~m}$ combined, i.e. canopy cover $>2 \mathrm{~m}$;

- Shrub;

- Grass;

- Areas with a slope length $>100 \mathrm{~m}$; and

- Roads.

\section{Polygon Status Mapping}

- Category 1: If slope length $>100 \mathrm{~m}$ and / or gullies are present within polygon.

- Category 2: Remaining polygons not classified yet

- Category 2: If bare ground objects $>500 / 1000 \mathrm{~m}^{2}$ or bare ground covering $>50 \%$ of polygon within polygon.

- Category 3: Remaining polygons not classified yet.

- Category temp: Category 3 polygons having either:

- Ground and canopy cover $>50 \%$;

- Canopy cover (trees $>2 \mathrm{~m}$ ) $>5 \%$;

- Canopy cover $>$ "Tree $>4 \mathrm{~m}$ cover" class (indicating two canopy height classes); or

- Road cover $=0$.

- If these conditions were not fulfilled, Category 3 polygons remain as Category 3.

- Category 5: If Category temp polygons fulfil the following criteria (i.e. indicators D-H in Table 2):

- Ground and canopy cover $>50 \%$;

- Canopy cover (trees $>2 \mathrm{~m}$ ) $>5 \%$;

- Trees 2-4 $m$ cover $>0 \%$;

- Tree $>4 \mathrm{~m}$ cover $>0 \%$; and

- Road cover $=0$.

- If these conditions were not fulfilled, Category temp polygons are classified as Category 4.

Figure 7. Flowchart of the approach used to categorise the mine site polygon status into five different safety, stability and sustainability levels. 
The automated mapping approach was set up to sequentially evaluate the criteria for each category, starting with Category 1. If that was satisfied, the criteria for Category 2 were checked and so on. Once the criteria for a category were no longer fulfilled, the polygon was assigned to this category (Figure 7). For the whole Ivanhoe North site, both images were assigned as Category 2, indicating no change and that the site was safe, i.e. no significant slopes and gullies, but not stable and sustainable. The Category 2 labelling of the Ivanhoe North site was caused by the contiguous bare ground $>500 \mathrm{~m}^{2}$ (see Figure 4).

The maps generated for the Curragh site produced polygons with poor status in most cases (i.e. Category 1), due to the presence of gully erosion, indicating a lack of safety, stability and sustainability (Figure 8). Most of the areas of bare ground had gully erosion and showed signs of rill development. Some of the areas with rills developed into gullies between the acquisition of images 1 and 3 , following exposure of the site to a controlled fire. Without the fire and gully erosion, most of the polygons would have been categorised with a status score one to three categories higher. The Category 4 polygon in the south-western part of image 1 changed to Category 2 in image 2 (Figure 8) due to the presence of mapped bare ground patches $>1000 \mathrm{~m}^{2}$, but went back to a Category 4 in image 3 due to a reduction in mapped bare ground. Both of the two Category 2 labelled polygons in image 1 in the north-eastern and south-eastern parts of the imaged area were reduced to a Category 1 status because of gully development within these two polygons in the subsequent images.
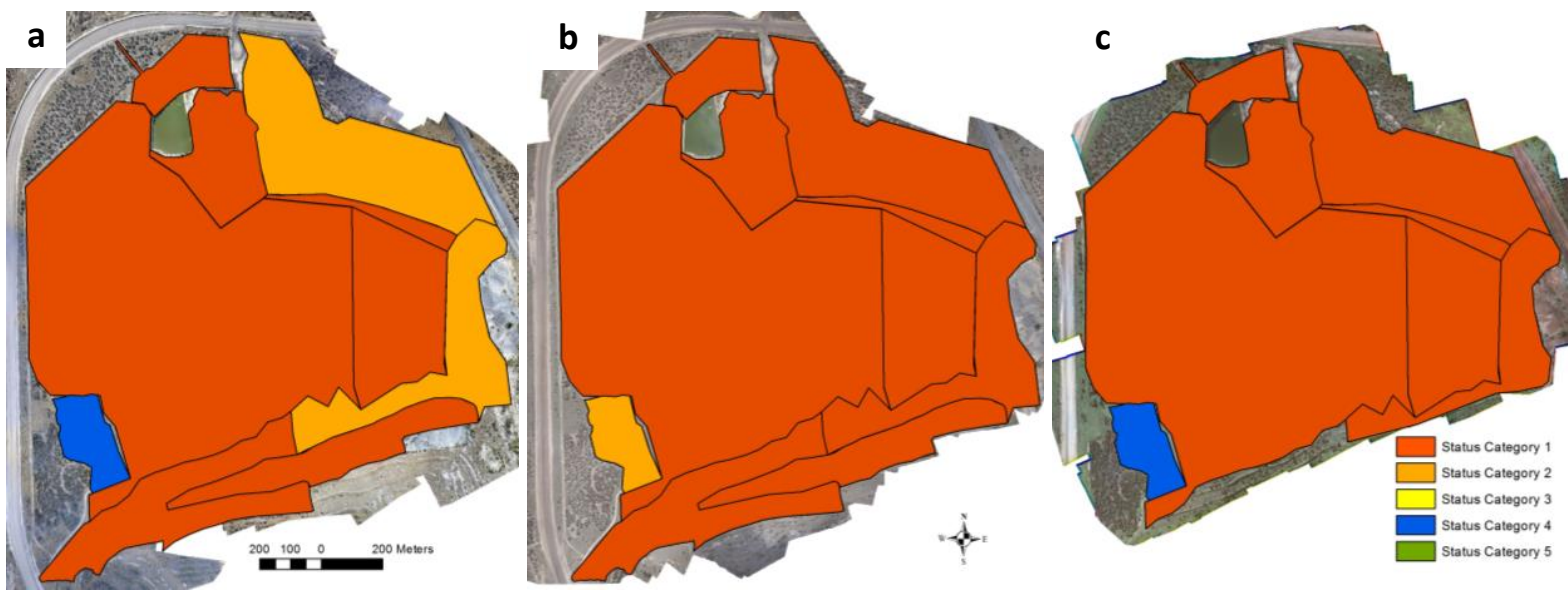

Figure 8. Polygon based status maps of the Curragh site for images 1 (a), 2 (b) and 3 (c).

The polygon status maps for Meandu (Figure 9) should be interpreted in relation to the mapping accuracies previously reported (Tables A6-A7). While the decrease in mapped trees $>2 \mathrm{~m}$ is to some extent attributed to the inability to map these accurately in image 2 , a significant patch (approximately $3 \mathrm{ha}$ ) of Acacia trees in the western part of the site was cleared prior to the collection of image 2 . This was the main contributor to the reduction in the category status from 4 to 2 for this polygon. The other polygons with a Category 4 status in image 1 and a Category 2 status in image 2 appeared with the lower status score because of the exposure of more bare ground with contiguous patches over $500 \mathrm{~m}^{2}$ in image 2 . The two polygons with a Category 1 status in image 1 was caused by sloping ground, which did not occur in image 2 , hence increasing the status score to Category 2 for these two polygons. 

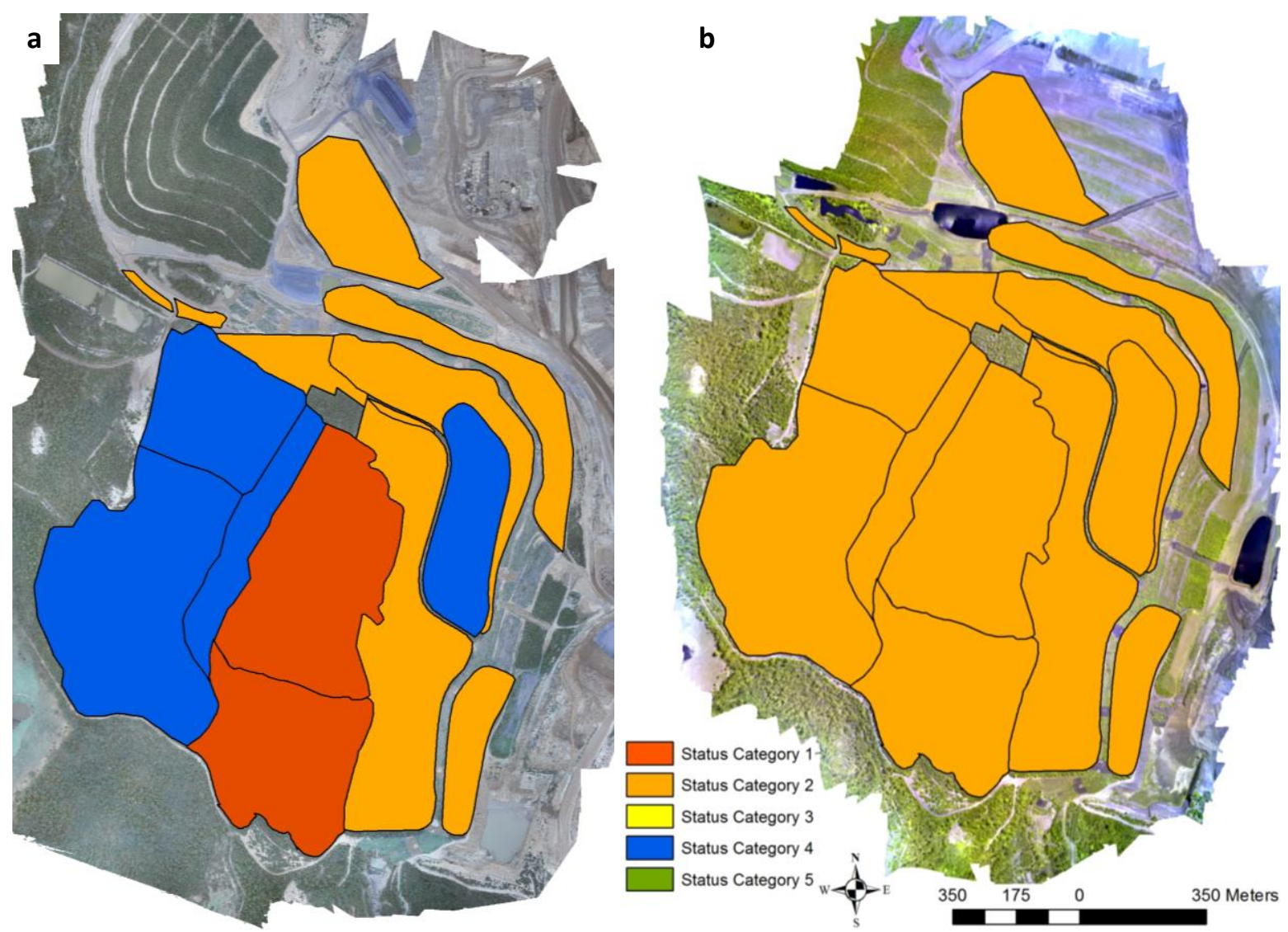

Figure 9. Polygon based status maps of the Meandu site for images 1 (a) and 2 (b).

While the status maps provide a quick overview that can be used to assess changes and rehabilitation progress over time, it is important to include the maps of land-cover, vegetation structure and landform characteristics to properly interpret the status categories. During the rehabilitation process, which may occur over multiple decades, multi-temporal imagery and derived status maps allow identification of sites, requiring remedial action, where the detailed land-cover maps can be used as a guide to determine management implications at different spatial scales. As highlighted for the Curragh site, polygons can change their status in response to fire and other natural disturbances that are beyond management control. To use these status maps to support the relinquishment of a mine lease, it is therefore important to have consistently high status scores for multiple years and for a rehabilitated mine site to be able to recover quickly after fire and other natural disturbance events. A time-series of status and land-cover maps may also be used for negotiated residual risk assessments at the relinquishment stage (Lamb et al, 2015), to determine the residual risk payment by the leasing company for covering potential long-term costs of managing the final site. As this payment depends on the level of demonstrated certainty of landforms remaining stable and the sustainability of the site, a time-series of UAV based status and land-cover maps with complete spatial coverage may provide more convincing evidence than field data, covering selected parts of a mine rehabilitation site. Regulators may often lack adequate tools to assess compliance and sustainability of rehabilitation. Hence, this research may also support regulatory authorities that require validation of rehabilitation achievements claimed by mining companies. The main benefit of the developed approach is that it can be used by both mining companies and regulators at different spatial scales, for both small and large polygons, as long as the specific thresholds for the indicators outlined in Table 2 are adjusted accordingly. 
Future work may focus on integrating additional status indicators of safety, stability and sustainability to provide a more detailed mine site rehabilitation status assessment. These additional indicators could include: information on vegetation composition, presence of invasive species, similarity to original vegetation, biodiversity and establishment of ecosystems, rates of landform and vegetation change under a disturbance regime (e.g. grazing, fire, flood events); presence of voids or tunnel erosion; soil and spoil metal and salt concentrations; and void water quality. The inclusion of these additional status indicators, especially with regards to species richness and composition and the presence of invasive species or similarity to original vegetation, may improve the developed framework and ability to evaluate rehabilitation success. This additional information might particularly affect the ability to successfully discriminate between status categories 4 and 5 related to the level of sustainability.

It is also recommended to explore how to further increase the mapping accuracies, e.g. by performing radiometric corrections to normalize image digital numbers to at-surface reflectance (similar to Johansen et al., 2018), and by optimizing UAV flight acquisition configurations (height, speed, sidelap, time of year and day, camera type, etc.) to increase the accuracy of the Structure-from-Motion derived DSMs. As a guideline for landscape monitoring, imagery collected at anniversary dates or within anniversary windows should be used in order to reduce changes occurring due to rainfall, temperature, plant phenology, solar geometry, etc. (Coppin and Bauer, 1996). In terms of timing for detecting vegetation status, data collection of mine rehabilitation sites should occur soon after the wet season (particularly if grazing or biomass are important for the polygon status) to reflect maximum photosynthetic cover. To detect bare ground and gully change at mine rehabilitation sites, it is recommended that data collection occurs at the end of the dry season when vegetation cover is lowest and safety and stability of the polygon status are of highest importance.

\section{Conclusions}

An automated multi-temporal monitoring method was developed to assess the safety, stability and sustainability levels of mine site rehabilitation. The developed framework provides a new approach for using UAV derived land-cover and landform classes, together with vegetation structural information, to determine whether rehabilitated land is appropriately conditioned for post-mining use. It was integrated as a part of an automated mapping method so that a map with five status categories of selected polygons within a mine rehabilitation site could be produced. Importantly, the framework and automated mapping method offer the capacity to be applied to a range of mine rehabilitation cases, is not site-specific, and is therefore transferable to other locations and scenarios. However, it is important that the UAV imagery is collected with flight acquisition configurations that optimize the accuracy of the Structure-from-Motion derived DSMs to allow accurate discrimination of trees, shrub and grass based on height information. The derived maps can be used for both identification of site locations requiring further management action and to demonstrate rehabilitation achievements with complete spatial coverage. With the increasing use of UAVs for mine rehabilitation monitoring, the developed UAV based framework has potential to support many future applications, including management implications, legislative compliance, negotiated residual risk assessments and mine lease relinquishment. 


\section{Acknowledgements}

We would like to thank Andrew Fletcher for help to develop this project and for collecting and processing UAV imagery. The Australian Coal Industry's Research Program (ACARP) monitors helped us develop site specific criteria and access sites and data. Funding to undertake this work was provided by ACARP through their support of Project C24031.

\section{References}

Ahmed, O.S., Shemrock, A., Chabot, D., Dillon, C., Williams, G., Wasson, R., Franklin, S.E. (2017). Hierarchical land cover and vegetation classification using multispectral data acquired from an unmanned aerial vehicle. International Journal of Remote Sensing, 38(8-10), 2037-2052.

Bagheri, N. (2017). Development of a high-resolution aerial remote-sensing system for precision agriculture. International Journal of Remote Sensing, 38(8-10), 2053-2065.

Bao, N., Lechner, A.M., Johansen, K., Ye, B. (2014). Object-based classification of semi-arid vegetation to support mine rehabilitation and monitoring. Journal of Applied Remote Sensing, 8 , 083564-1.

Blaschke (2010). Object based image analysis for remote sensing. ISPRS Journal of Photogrammetry and Remote Sensing, 65(1), 2-16.

Chen, J., Li, K., Chang, K.-J., Sofia, G., Tarolli, P. (2015). Open-pit mining geomorphic feature characterisation. International Journal of Applied Earth Observation and Geoinformation, 42, 76-86.

Chen, W., Li, X., He, H., Wang, L. (2018). A review of fine-scale land use and land cover classification in open-pit mining areas by remote sensing techniques. Remote Sensing, 10(1), 15.

Congultan, R.G., Green, K. (1999). Assessing the accuracy of remotely sensed data: Principles and practices. CRC Press, Inc., Boca Raton, USA.

Coppin, P.R., Bauer, M.E. (1996). Change detection in forest ecosystems with remote sensing digital imagery. Remtoe Sensing Reviews, 13, 207-234.

Esposito, G., Mastrorocco, G., Salvini, R., Oliveti, M., Starita, P. (2017). Application of UAV photogrammetry for the multi-temporal estimation of surface extent and volumetric excavation in the Sa Pigada Bianca open-pit mine, Sardinia, Italy. Environmental Earth Sciences, 76, 103.

Erskine, P.D., Fletcher, A.T. (2013) Novel ecosystems created by coal mines in central Queensland's Bowen Basin. Ecological Processes, 2(33), 1-12.

Fletcher, A.T., Erskine, P.D. (2013). Rehabilitation closure criteria assessment using high resolution photogrammetrically derived surface models. International Archives of the Photogrammetry, 
Remote Sensing and Spatial Information Sciences, Volume XL-1/W2, UAV-g 2013, 4-6 September 2013, Rostock, Germany.

Freeburn, M., Mather, R. (2011). Utilisation of high resolution infrared imagery for the enhanced monitoring of revegetation in open-cut mine site rehabilitation. Project C14055, Australian Coal Association Research Program.

Gastauer, M., Silva, J.R., Caldeira Junior, C.F., Ramos, S.J., Filho, P.W.M.S., Neto, A.E.F., Siqueira, J.O. (2018). Mine land rehabilitation: modern ecological approaches for more sustainable mining. Journal of Cleaner Production, 172, 1409-1422.

Gravina, A., Vickers, H. (2010). Tarong coal Meandu mine rehabilitation monitoring and compliance with EA criteria 2010 assessment. Report to Tarong Energy Corporation. The University of Queensland.

Jimenez-Brenes, F.M., Lopez-Granados, F., de Castro, A.I., Torres-Sanchez, J., Serrano, N., Pena, J.M. (2017). Quantifying pruning impacts on olive tree architecture and annual canopy growth by using UAV-based 3D modelling. Plant Methods, 13, 55.

Johansen, K., Phinn, S., Dixon, I., Douglas, M., Lowry, J. (2007). Comparison of image and rapid field assessments of riparian zone condition in Australian tropical savannas. Forest Ecology and Management, 240(1-3), 42-60.

Johansen, K., Bartolo, R., Phinn, S. (2010). Special Feature - Geographic object-based image analysis. Journal of Spatial Science, 55(1), 3-7.

Johansen, K., Raharjo, T., McCabe, M.F. (2018). Using multi-spectral UAV imagery to extract tree crop structural properties and assess pruning effects. Remote Sensing, 10(6), 854.

Kerr, J.T., Ostrovsky, M. (2003). From space to species: ecological applications for remote sensing. Trends in Ecology and Evolution, 18(6), 299-305.

Koch, J.M., Hobbs, R.J. (2007). Synthesis: is Alcoa successfully restoring a Jarrah Forest ecosystem after bauxite mining in Western Australia? Restoration Ecology, 15(s4), S137-S144.

Lamb, D., Erskine, P.D., Fletcher, A. (2015). Widening gap between expectations and practice in Australian minesite rehabilitation. Ecological Management and Restoration, 16, 186-195.

McCabe, M., Rodell, M., Alsdorf, D.E., Miralles, D.G., Uijlenhoet, R., Wagner, W., Lucieer, A., Houborg, R., Verhoest, N.E.C., Franz, T.E., Shi, J., Gao, H., Wood, E.F. (2017). The future of Earth observation in hydrology. Hydrology and Earth System Sciences, 21, 3879-3914.

McKenna, P., Glenn, V. (2016). Curragh coal mine rehabilitation vegetation monitoring. Centre for Mined Land Rehabilitation for Wesfarmers Curragh Pty Ltd. 
McKenna, P., Glenn, V., Erskine, P.D., Doley, D., Sturgess, A. (2017a). Fire behaviour on engineered landforms stabilized with high biomass buffel grass. Ecological Engineering, 101, 237-246.

McKenna, P., Erskine, P.D., Lechner, A.M., Phinn, S. (2017b). Measuring fire severity using UAV imagery in semi-arid central Queensland, Australia. International Journal of Remote Sensing, 38(14), 4244-4264.

Neldner, V.J., Ngugi, M.R. (2014). Application of the BioCondition assessment framework to mine vegetation rehabilitation. Ecological Management and Restoration, 15, 158-161.

NSW Government (2017). Rehabilitation Cost Estimation Tool. https://resourcesandgeoscience.nsw.gov.au/miners-and-explorers/rules-andforms/pgf/environmental-guidelines [Accessed 28 August, 2018].

Otto, J.M. (2009). Global trends in mine reclamation and closure regulation. In: Richards J. (eds) Mining, society, and a sustainable world. Springer, Berlin, Heidelberg.

Pajares, G. (2015). Overview and current status of remote sensing applications based on Unmanned Aerial Vehicles (UAVs). Photogrammetric Engineering and Remote Sensing, 81, 281-330.

Pickup, G., Chewings, V.H., Nelson, D.J. (1993). Estimating changes in vegetation cover over time in arid rangelands using Landsat MSS data. Remote Sensing of Environment, 43(3), 243-263.

Pix4D (2018). How to improve the outputs of dense vegetation areas? https://support.pix4d.com/hc/en-us/articles/202560159-How-to-improve-the-outputs-of-densevegetation-areas- [Accessed 28 August, 2018].

Rossi, P., Mancini, F., Dubbini, M., Mazzone, F., Capra, A. (2017). Combining nadir and oblique UAV imagery to reconstruct quarry topography: methodology and feasibility analysis. European Journal of Remote Sensing, 50(1), 211-221.

Suh, J., Kim, S.-M., Yi, H., Choi, Y. (2017). An overview of GIS-based modelling and assessment of mining-induced hazards: soil, water, and forest. International Journal of Environmental Research and Public Health, 14, 1463.

Torres-Sanchez, J., Lopez-Granados, F., Serrano, N., Arquero, O., Pena, J.M. (2015). High-throughput 3-D monitoring of agricultural-tree plantations with Unmanned Aerial Vehicle (UAV) technology. PLOS ONE, 10(6), e0130479.

von Bueren, S.K., Burkart, A., Hueni, A., Rascher, U., Tuohy, M.P., Yule, I.J. (2015). Deploying four optical UAV-based sensors over grassland: Challenges and limitations. Biogeosciences, 12(1), 163175.

Whiteside, T.G., Bartolo, R.E., Erskine, P., Fletcher, A. (2014). Object-based characterisation of reference site for mine site closure using hyperspatial multispectral UAV imagery. South-Eastern European Journal of Earth Observation and Geomatics, 3(2), 119-123. 
Whiteside, T.G., Bartolo, R.E. (2016). Robust and repeatable ruleset development for hierarchical object-based monitoring of revegetation using high spatial and temporal resolution UAS data. Geographic Object-Based Image Analysis (GEOBIA) Conference, 2016, Twente, Netherlands.

Zhang, C., Kovacs, J. (2012). The application of small Unmanned Aerial Systems for precision agriculture: A review. Precision Agriculture, 13(6), 693-712. 


\section{Appendix}

Table A1. Accuracy assessment of Ivanhoe North image 1. Overall accuracy $=85 \%$.

\begin{tabular}{|c|c|c|c|c|c|c|}
\hline Classified \Reference & Bare Ground & Grass & Shrub $<2 \mathrm{~m}$ & Trees $>2 \mathrm{~m}$ & Water & Total \\
\hline Bare Ground & 30 & & & & & 30 \\
\hline Grass & & 24 & 9 & & & 33 \\
\hline Shrub $<2 \mathrm{~m}$ & & 6 & 14 & 1 & & 21 \\
\hline Trees $>2 m$ & & & 7 & 29 & & 36 \\
\hline Water & & & & & 31 & 31 \\
\hline Total & 30 & 30 & 30 & 30 & 31 & 151 \\
\hline User Accuracy & $100 \%$ & $72.7 \%$ & $66.7 \%$ & $80.6 \%$ & $100 \%$ & \\
\hline Producer Accuracy & $100 \%$ & $80 \%$ & $46.7 \%$ & $96.7 \%$ & $100 \%$ & \\
\hline
\end{tabular}

Table A2. Accuracy assessment of Ivanhoe North image 2. Overall accuracy $=87 \%$.

\begin{tabular}{|c|c|c|c|c|c|c|}
\hline Classified\Reference & Bare Ground & Grass & Shrub $<2 \mathrm{~m}$ & Trees $>\mathbf{2} \mathrm{m}$ & Water & Total \\
\hline Bare Ground & 29 & 3 & 1 & 1 & 2 & 36 \\
\hline Grass & & 21 & 3 & 2 & & 26 \\
\hline Shrub $<2 \mathrm{~m}$ & & 3 & 24 & & & 27 \\
\hline Trees $>2 m$ & & 2 & 2 & 27 & & 31 \\
\hline Water & & & & & 28 & 28 \\
\hline Total & 29 & 29 & 30 & 30 & 30 & 148 \\
\hline User Accuracy & $80.6 \%$ & $80.8 \%$ & $88.9 \%$ & $87.1 \%$ & $100 \%$ & \\
\hline Producer Accuracy & $100 \%$ & $72.4 \%$ & $80 \%$ & $90 \%$ & $93.3 \%$ & \\
\hline
\end{tabular}

Table A3. Accuracy assessment of Curragh image 1. Overall accuracy $=45 \%$.

\begin{tabular}{lllllll}
\hline Classified\Reference & $\begin{array}{l}\text { Bare } \\
\text { Ground }\end{array}$ & Grass & Shrub $<\mathbf{2} \mathbf{m}$ & Trees $>\mathbf{2} \mathbf{m}$ & $\begin{array}{l}\text { Senescent } \\
\text { Vegetation }\end{array}$ & Total \\
\hline Bare Ground & 19 & 4 & 5 & 4 & 8 & 40 \\
Grass & 10 & 23 & & 6 & 15 & 54 \\
Shrub $<\mathbf{2}$ m & & & 7 & 1 & & 8 \\
Trees $>$ 2m & 2 & & 3 & 6 & 1 & 12 \\
Senescent Veg & 9 & 4 & 3 & 13 & 16 & 45 \\
\hline Total & 40 & 31 & 18 & 30 & 40 & 159 \\
\hline User Accuracy & $47.5 \%$ & $42.6 \%$ & $87.5 \%$ & $50 \%$ & $40 \%$ & \\
Producer Accuracy & $47.5 \%$ & $74.2 \%$ & $38.9 \%$ & $20 \%$ & $40 \%$ & \\
\hline
\end{tabular}

Table A4. Accuracy assessment of Curragh image 2. Overall accuracy $=73 \%$.

\begin{tabular}{lllllll}
\hline Classified\Reference & $\begin{array}{l}\text { Bare } \\
\text { Ground }\end{array}$ & Grass & Shrub $<\mathbf{2} \mathbf{m}$ & Trees $>\mathbf{2} \mathbf{m}$ & $\begin{array}{l}\text { Senescent } \\
\text { Vegetation }\end{array}$ & Total \\
\hline Bare Ground & 32 & & & & 1 & 33 \\
Grass & & 32 & 18 & & 22 & 52 \\
Shrub $<\mathbf{2}$ m & & & 12 & 1 & & 13 \\
Trees $>$ 2m & & & 1 & 29 & & 30 \\
Senescent Veg & & 1 & & & 14 & 15 \\
\hline Total & 32 & 33 & 31 & 30 & 37 & 163 \\
\hline User Accuracy & $97 \%$ & $61.5 \%$ & $92.3 \%$ & $96.7 \%$ & $93.3 \%$ & \\
Producer Accuracy & $100 \%$ & $97 \%$ & $38.7 \%$ & $96.7 \%$ & $37.8 \%$ & \\
\hline
\end{tabular}


Table A5. Accuracy assessment of Curragh image 3. Overall accuracy $=83 \%$.

\begin{tabular}{lllllll}
\hline Classified\Reference & $\begin{array}{l}\text { Bare } \\
\text { Ground }\end{array}$ & Grass & Shrub $<\mathbf{2} \mathbf{m}$ & Trees $>\mathbf{2} \mathbf{m}$ & $\begin{array}{l}\text { Senescent } \\
\text { Vegetation }\end{array}$ & Total \\
\hline Bare Ground & 32 & & & & 3 & 35 \\
Grass & & 30 & 16 & & & 46 \\
Shrub $<\mathbf{2} \mathbf{m}$ & & 1 & 6 & 4 & & 11 \\
Trees $>\mathbf{2 m}$ & & 1 & & 31 & & 32 \\
Senescent Veg & & 1 & & & 30 & 31 \\
\hline Total & 32 & 33 & 22 & 35 & 33 & 155 \\
\hline User Accuracy & $91.4 \%$ & $65.2 \%$ & $54.5 \%$ & $96.9 \%$ & $96.8 \%$ & \\
Producer Accuracy & $100 \%$ & $90.9 \%$ & $27.3 \%$ & $88.6 \%$ & $90.9 \%$ & \\
\hline
\end{tabular}

Table A6. Accuracy assessment of Meandu image 1. Overall accuracy $=80 \%$.

\begin{tabular}{lllllll}
\hline Classified\Reference & $\begin{array}{l}\text { Bare } \\
\text { Ground }\end{array}$ & Grass & Shrub $<\mathbf{2} \mathbf{m}$ & Trees $>\mathbf{2} \mathbf{m}$ & $\begin{array}{l}\text { Senescent } \\
\text { Vegetation }\end{array}$ & Total \\
\hline Bare Ground & 30 & 1 & & & 9 & 40 \\
Grass & & 15 & 5 & & 3 & 23 \\
Shrub $<\mathbf{2}$ m & & 1 & 23 & & 2 & 26 \\
Trees $>$ 2m & & 2 & 3 & 28 & 2 & 35 \\
Senescent Veg & & 1 & & 1 & 21 & 23 \\
\hline Total & 30 & 20 & 31 & 29 & 37 & 147 \\
\hline User Accuracy & $75 \%$ & $65.2 \%$ & $88.5 \%$ & $80 \%$ & $91.3 \%$ & \\
Producer Accuracy & $100 \%$ & $75 \%$ & $74.2 \%$ & $96.6 \%$ & $56.8 \%$ & \\
\hline
\end{tabular}

Table A7. Accuracy assessment of Meandu image 2. Overall accuracy $=68 \%$.

\begin{tabular}{lllllll}
\hline Classified\Reference & $\begin{array}{l}\text { Bare } \\
\text { Ground }\end{array}$ & Grass & Shrub $<\mathbf{2} \mathbf{m}$ & Trees $>\mathbf{2} \mathbf{m}$ & $\begin{array}{l}\text { Senescent } \\
\text { Vegetation }\end{array}$ & Total \\
\hline Bare Ground & 28 & & & & 6 & 34 \\
Grass & & 28 & 13 & 9 & 5 & 55 \\
Shrub $<\mathbf{2} \mathbf{m}$ & & 2 & 11 & 3 & & 16 \\
Trees $>$ 2m & & 1 & 2 & 20 & & 23 \\
Senescent Veg & & 2 & 7 & 1 & 19 & 29 \\
\hline Total & 28 & 33 & 33 & 33 & 30 & 157 \\
\hline User Accuracy & $82.4 \%$ & $50.9 \%$ & $68.8 \%$ & $87 \%$ & $65.5 \%$ & \\
Producer Accuracy & $100 \%$ & $84.8 \%$ & $33.3 \%$ & $60.6 \%$ & $63.3 \%$ & \\
\hline
\end{tabular}

